\title{
EFFECT OF DIFFERENT WOOD DOWELS ON MECHANICAL PROPERTIES OF TRIANGULAR GIRDER TRUSSES
}

\author{
Liuliu Zhang, Cheng Chang, Shuming Yang, \\ Tongyu Hou, Yifan Liu, Zeli Que \\ Nanjing Forestry University \\ China
}

(Received July 2020)

\begin{abstract}
Static load tests were carried out on three kinds of triangular girder trusses with different diameter wood dowels, and the effects of that on the structure of girder trusses were discussed. It was found that there was a good synergy between the wood dowels and the girder trusses. Among the triangular girder trusses with different diameters, the $16 \mathrm{~mm}$ diameters had the best energy dissipation performance increased by $184 \%$ and deformation resistance of $0.73 \mathrm{~mm}$; the $20 \mathrm{~mm}$ diameters had the best stability performance, the better bearing capacity of $60.42 \mathrm{kN}$ and deformation resistance of $0.82 \mathrm{~mm}$. The bearing capacity of the double girder trusses was 2.06-2.25 times that of two single trusses, which had the ability to 'one plus one is greater than two'.
\end{abstract}

KEYWORDS: Triangular girder truss, truss joint, anti-deformation capability, load-carrying capacity. 


\section{INTRODUCTION}

Wood structure building is an important representative of ecological architecture. In order to save energy, reduce emissions, relieve the pressure on the environments and resources in the whole life cycle of buildings and achieve the recycling and sustainable development of materials, the promotion and application of wood structures has become a consensus of the whole society (Yang et al.2020).

As one of the main forms of modern wood structure, light wood frame construction has excellent dimension lumber processing, certification system and mature prefabricated component manufacturing technology (Madsen 1992) compared with heavy timber construction. Furthermore, it also has the advantages of short construction cycle and low cost (Prochazka et al. 2014). Among them, light wood trusses are one of the main load-carrying components of light wood frame construction. Nowadays, more than $60 \%$ of residential buildings in North America use wood trusses, of which about $95 \%$ of new residential buildings in Canada are built with wood trusses. In addition, wood trusses have been widely used in Europe, Asia and other regions. With the widespread application of light wood frame construction, the application of wood trusses in modern buildings has become more and more extensive. However, the load-carrying capacity of common triangular wood trusses is limited that the suitable span of Howe type wood trusses with the best mechanical performance is no more than $12 \mathrm{~m}$. This limits the scope of application of light wood frame construction roof system and also hinders the promotion and development of wood trusses to some extent. The appearance of triangular girder trusses has effectively solved these problems. By combining several trusses of common triangular wood trusses into one structural component, the section size of the component could be increased to obtain better load-carrying capacity, deformation resistance and stability, so as to meet the requirements of larger span (Zhang et al. 2012, Yang 2014, Que et al. 2015, He et al. 2015).

At present, researches on wood trusses mostly focus on the repair technology, metal tooth plate connection of single truss and light wood truss system. In contrast, the study of girder trusses has hardly been involved (Gupta et al. 2005, Gupta et al. 2004, Rittenburg et al. 2003, Via et al. 2001, Munafoet et al. 2015, Fauziyah et al. 2016, Underwood et al. 2001, Song et al. 2012, Gupta et al. 2004, Cabrero et al. 2009, Islam et al. 2017, Mohamadzadeh et al. 2015, Guntekin 2007, 2009, Sandanus et al. 2016, Moya et al. 2017) due to the common use of girder trusses in engineering, which has no design value reference. This raises several security issues. In the previous study (Wang et al.2019, Gao 2017), the team members found that the connection of parallel chord girder trusses connected with wood dowels had a good synergistic effect and could effectively solve the instability problem of a single truss. So in order to explore the connection mode and performance between the trusses with different structural forms, this paper conducts experimental research on triangular girder trusses.

\section{MATERIAL AND METHODS}

In order to explore the influence of the mechanical properties of triangular girder trusses with different diameter wood dowels, static loading tests were carried out on the Fink double trusses with $6 \mathrm{~m}$ span and $1.5 \mathrm{~m}$ height of different connection modes according to GB/T 50329 (2012). The number and identifier of specimens were shown in Tab. 1. Among them, ST stands for single truss, GT for girder truss. 
Vol. 66 (3): 2021

Tab. 1: Number and identifier of trusses.

\begin{tabular}{|l|c|c|c|c|}
\hline Type of trusses & Two single trusses & \multicolumn{3}{|c|}{ Double girder trusses } \\
\hline Wood dowel & - & $16 \mathrm{~mm}$ & $18 \mathrm{~mm}$ & $20 \mathrm{~mm}$ \\
\hline \multirow{2}{*}{ Identifier } & ST-1 & GT-D16-1 & GT-D18-1 & GT-D20-1 \\
\cline { 2 - 5 } & ST-2 & GT-D16-2 & GT-D18-2 & GT-D20-2 \\
\hline
\end{tabular}

\section{Materials}

The material used in the test was Larix gemlimii, imported from Russia. The material grade was class II, section sizes were $38 \mathrm{~mm}$ x $89 \mathrm{~mm}$. According to GB/T 50329 (2012), material parameters of the specimen were shown in Tab. 2 . The density was $0.657 \mathrm{~g}_{\mathrm{cm}}{ }^{-3}$, and the moisture content was $17.4 \%$, according to GB/T 1928 (2009). The tooth plates used in the experiment were galvanised and made in China. The performance parameters were shown in Tab. 3.

Tab. 2: Material parameters of specimens (units: $\mathrm{MPa}$ ).

\begin{tabular}{|l|c|c|c|c|}
\hline Modulus of elasticity & Modulus of rupture & $\begin{array}{c}\text { Compressive strength } \\
\text { along grain }\end{array}$ & $\begin{array}{c}\text { Tensile strength } \\
\text { along grain }\end{array}$ & $\begin{array}{c}\text { Transverse } \\
\text { compressive strength }\end{array}$ \\
\hline $12220.9 \pm 6.21^{*}$ & $85.32 \pm 1.18^{*}$ & $45.15 \pm 4.3^{*}$ & $10.21 \pm 1.25^{*}$ & $7.6 \pm 1.8^{*}$ \\
\hline
\end{tabular}

*Standard deviation.

Tab. 3: Performance parameters of tooth plate.

\begin{tabular}{|c|c|c|c|c|}
\hline $\begin{array}{c}\text { Tooth plate thickness } \\
(\mathbf{m m})\end{array}$ & $\begin{array}{c}\text { Density of plate teeth } \\
\left(\mathbf{e a c h} / \mathbf{m m}^{\mathbf{2}}\right)\end{array}$ & $\begin{array}{c}\text { Length of plate teeth } \\
(\mathbf{m m})\end{array}$ & $\begin{array}{c}\text { Elastic modulus } \\
\text { of steel } \\
(\mathbf{G P a})\end{array}$ & $\begin{array}{c}\text { Tensile yield strength } \\
\text { of steel } \\
(\mathbf{M P a})\end{array}$ \\
\hline 0.90 & 0.012 & 8.6 & 203 & 248 \\
\hline
\end{tabular}

\section{Specimen processing}

The single truss was connected by tooth plates, which was first positioned manually and then pressed by a flat press with a pressure of $13 \mathrm{MPa}$. The processing of girder truss was based on two single trusses that were stacked. The joint position was drilled out in advance to ensure that the hole diameter was $0.5 \mathrm{~mm}$ smaller than wood dowels, which ensured a tight connection. The location of wood dowels in Fig. 1 was selected according to the mechanical characteristic of the truss joints. On this basis, a pistol drill or bench drill was used to drill wood dowels into the holes to form joints. Among them, The wood dowel was Fagus sylvatica with a diameter of $16 \mathrm{~mm}, 18 \mathrm{~mm}$ or $20 \mathrm{~mm}$ and a length of $80 \mathrm{~mm}$.

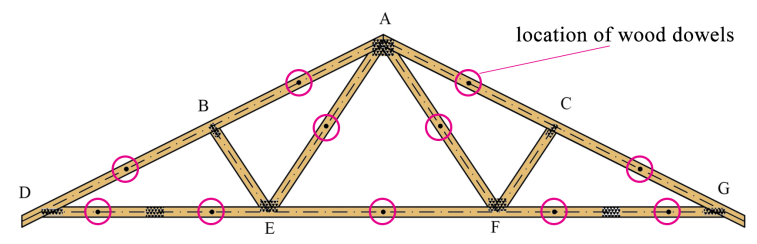

Fig. 1: The dowel joints location.

\section{Loading system and device}

The test was carried out based on the method of hierarchical loading test for trusses in the standard for test methods of timber structures GB/T 50329 (2012), and the loading system was shown in Fig. 2, where $P_{k}$ was calculated according to the Load code for the design of building structures GB 50009 (2012), and the result was $P_{k}=4.6 \mathrm{kN}$. 


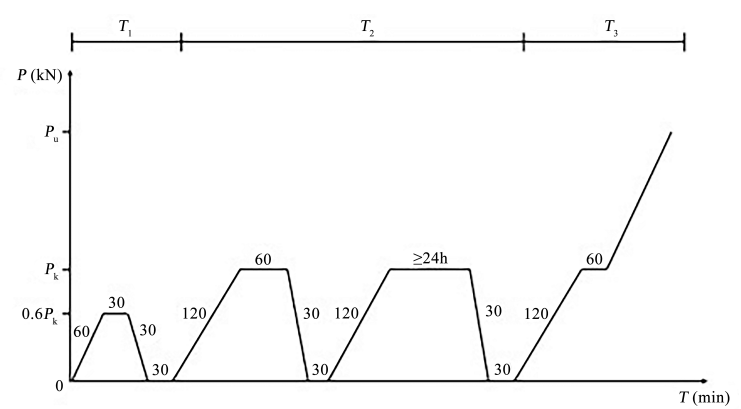

Fig. 2: Continuous loading system according to GB/T 50329 (2012).

The loading procedure was divided into three stages: pre-loading stage $T_{1}$, standard loading stage $T_{2}$ and destructive loading stage $T_{3}$ (Fig. 2). The loading device in Fig. 3 was designed on the basis of the microcomputer-controlled elector-hydraulic servo combined shear wall experimental system. Due to the large span of the truss and its poor stability during loading, o ensure the test, the anti-roll device was essential for the loading of the wood trusses. Based on comprehensive laboratory conditions, this study designed an anti-roll device suitable for this test based on the supporting device that comes with the test machine, as shown in Fig. 3b. The screw was used to connect the anti-rolling wood strip to the support device of the testing machine itself, and to ensure that the wood strip was infinitely close to the truss, so that every part of the truss was laterally supported, ensuring the stability of the entire truss load.

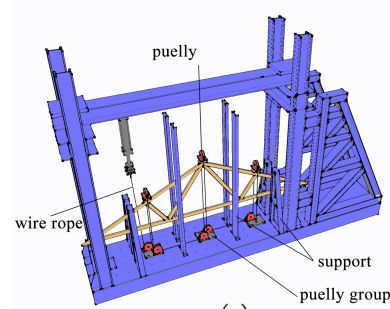

(a)

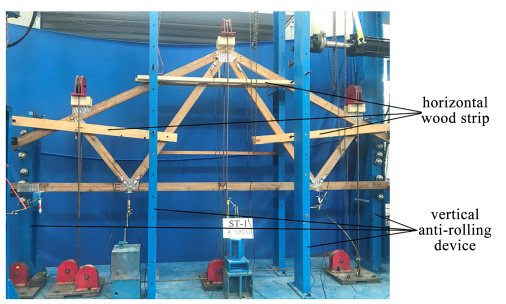

(b)

Fig. 3: Loading device: (a) design drawings device, (b) practical setting.

\section{RESULTS AND DISCUSSION}

\section{Analysis of experimental phenomena}

The trusses under preloading stage $T_{1}$ and standard loading $T_{2}$ stages all showed good performance. While in the destructive loading stage $T_{3}$, the failure modes of trusses were the roughly same. The tooth of the metal tooth plate at the support joints D and G started to separate from the wood, finally occurring the tooth plate separation failure. ST-1 showed no obvious experimental phenomena in preloading stage $T_{1}$ and standard loading $T_{2}$ stages. When the load increased to about $5.50 \mathrm{kN}, \mathrm{G}$-joint (Fig. 4a) appeared slightly bulging. When the load increased $8.36 \mathrm{kN}, \mathrm{G}$-joint in Fig. 4b showed tooth plate separation failure. GT-D16-1 showed no obvious experimental phenomena in preloading stage $T_{1}$ and standard loading $T_{2}$ stages. When the load increased to about $12.90 \mathrm{kN}$, each tooth plate at D-joint (Fig. 5a) appeared slightly bulging. Meanwhile, the tooth plates of the double girder truss between the two single trusses also showed slightly bulging at G-joint (Fig. 5b). With the increase of the load, the tooth plates slightly bulged and gradually evolved into tooth plate separation. When the load reached $19.26 \mathrm{kN}$, each D-joint tooth plate (Fig. 5c) completely separated from the lower chord. 


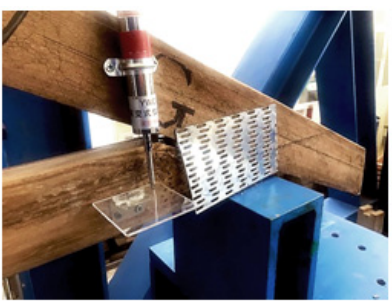

(a)

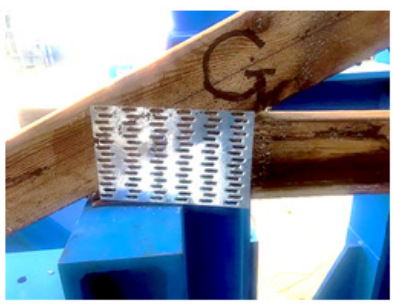

(b)

Fig. 4: The failure phenomena of ST-1: (a) load $5.50 \mathrm{kN}$, (b) load $8.36 \mathrm{kN}$.

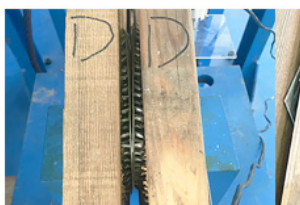

(a)

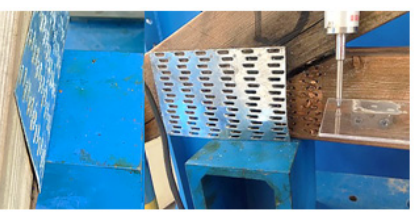

(c)

Fig. 5: The failure phenomena of GT-D16-1: (a) D-joint at $12.90 \mathrm{kN}$, (b) G-joint at $12.90 \mathrm{kN}$, (c) D-joint at $19.26 \mathrm{kN}$.

However, the test did not stop after the tooth plate separation failure at the support joint. Two single trusses lost the bearing performance, while the girder truss showed wood split failure at B-joint when the load reached about $P_{k}$. The phenomenon was shown in Fig. 6. It showed that compared with two single trusses, girder truss had better security performance. At the end of each test, the wood dowels were taken out, as shown in Fig. 7. The figure showed that there were no obvious phenomena in wood dowels. This meant the wood dowel could remain in the elastic range when the final damage occurred, so the coordination between the two single trusses could be maintained very well.

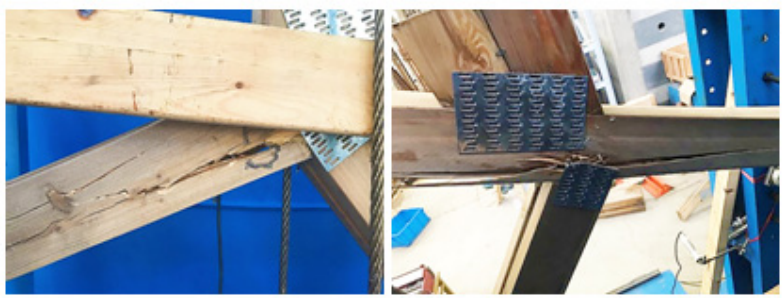

(a)

(b)

Fig. 6: Wood tearing failure under loading B-joint: (a) front, (b) back.

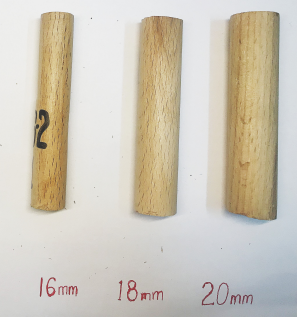

Fig. 7: Three kinds of wood dowels after test. 
In summary, all the wood trusses suffered from tooth plate separation failure at the support joints. When it continued loading after the damage, a second failure would occur at the loading point $\mathrm{B}$, indicating that the loading point was the second weakest link of the triangular wood truss. From the analysis of the axial force of single triangular wood truss (Fig. 8) could be seen that the axial forces at the rod ends of BD and CG were the largest, so the rod ends of $\mathrm{BD}$ and CG were the weakest part of the truss. The test results were consistent with the theoretical predictions.

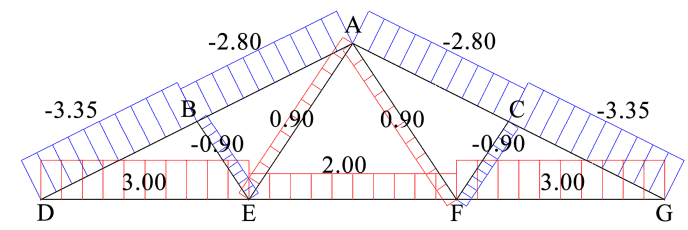

Fig. 8: The axial force of single triangular wood truss.

\section{Stability performance of truss}

As shown in Fig. 9, the mid-span deflection of the lower chord of each truss was obtained, showing that GT-D20 truss had the lowest degree of dispersion, which indicated that the performance of this kind was more stable. It was not difficult to find from the figure that the four types of trusses all showed normal test conditions, and had good consistency in first two stages, and the variability of wood made different types of trusses had different results in the third stage. From the mid-span load-deflection curves of $T_{1}$ and $T_{2}$ stages (Fig. 10) can be seen that the degree of dispersion of the curve was GT-D18 > GT-D16 > GT-D20 within the girder trusses. Combining the two curves found that the stability performance of $20 \mathrm{~mm}$ dowel-connected girder truss was the best.

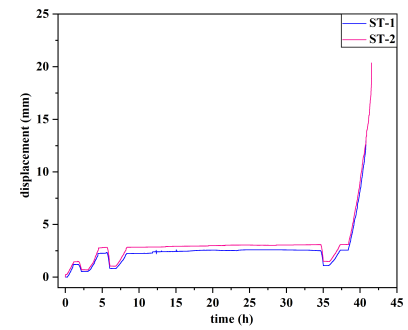

(a)

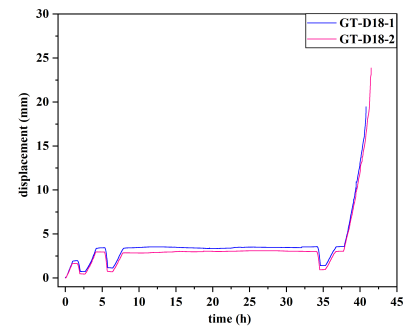

(c)

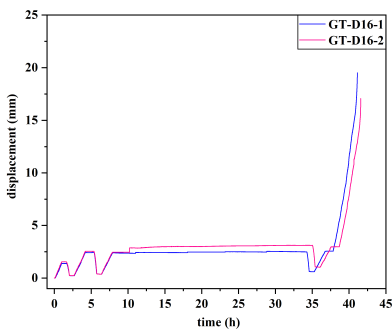

(b)

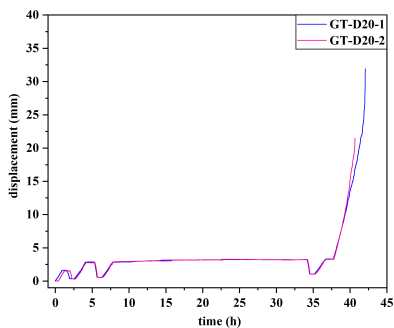

(d)

Fig. 9: Displacement variation in the middle of the lower chord span of each truss: (a) ST, (b) D16, (c) D18, (d) D20. 


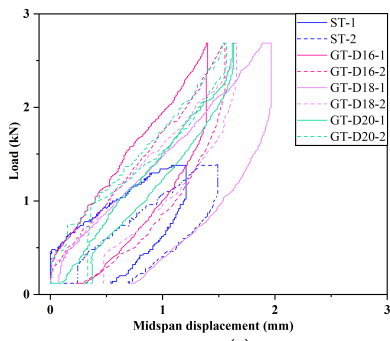

(a)

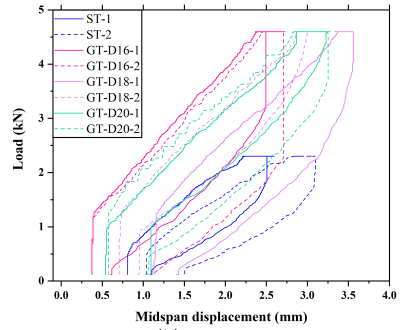

(b)

Fig. 10: The mid-span load-displacement curves: (a) T1 stage, (b) T2 stage.

\section{Energy dissipation performance of truss}

The area covered by the load-displacement curve in stage $T_{2}$ could be obtained, as shown in Tab. 4. The area represented the energy dissipation performance of the truss. From Tab. 4, it could be seen that the area covered by load displacement curve of GT-D16 truss was the largest, which showed the energy dissipation performance of the $16 \mathrm{~mm}$ dowel-connected triangular girder truss was the best. Compared with the energy dissipation performance of ST, GT-D16 increased by 184\%, GT-D18 increased by 165\%, and GT-D20 increased by $110 \%$. When the standard load had completed, each truss entered the stage of elastic recovery. After unloading and 30 minutes of no-load, each truss had plastic deformation. The elastic recovery size and the percentage of the recovery size to the end deflection of the continuous load were shown in Tab. 5. As could be seen, the elastic recovery capacity of double girder trusses was stronger than two single trusses, and all were above $60 \%$.

Tab. 4: Area wrapped in load-displacement curve of truss joints.

\begin{tabular}{|l|c|c|c|c|c|c|c|}
\hline \multirow{2}{*}{$\begin{array}{l}\text { Identifier } \\
\text { of truss }\end{array}$} & \multicolumn{7}{|c|}{$\begin{array}{c}\text { Area wrapped in load-displacement curve } \\
\text { (joints / } \mathbf{m m}^{\mathbf{2}} \text { ) }\end{array}$} \\
\cline { 2 - 9 } & Node A & Node B & Node C & Mid-span & Node E & Node F & Average \\
\hline ST & 1.29 & 1.25 & 1.26 & 1.96 & 1.22 & 1.19 & 1.36 \\
\hline GT-D16 & 3.77 & 4.37 & 3.60 & 5.21 & 2.91 & 3.30 & 3.86 \\
\hline GT-D18 & 4.31 & 3.81 & 3.53 & 4.06 & 3.08 & 2.79 & 3.60 \\
\hline GT-D20 & 2.01 & 3.06 & 2.51 & 4.70 & 2.53 & 2.34 & 2.86 \\
\hline
\end{tabular}

Tab. 5 : Elastic recovery of truss after unloading.

\begin{tabular}{|c|c|c|c|c|}
\hline \multirow[t]{2}{*}{ Identifier of truss } & \multicolumn{4}{|c|}{$\begin{array}{c}\begin{array}{c}\text { Elastic recovery size of lower chord } \\
\text { (joints } / \mathrm{mm} \text { ) }\end{array} \\
\end{array}$} \\
\hline & Mid-span & Node E & Node F & Average \\
\hline ST-1 & $1.42(55.3)$ & $1.13(59.2)$ & $1.16(65.9)$ & \multirow{2}{*}{$1.34(56.2)$} \\
\hline ST-2 & $1.62(52.1)$ & $1.42(56.3)$ & $1.24(52.5)$ & \\
\hline GT-D16-1 & $1.89(73.5)$ & $1.60(71.4)$ & $1.60(71.7)$ & \multirow{2}{*}{$1.64(66.9)$} \\
\hline GT-D16-2 & $1.68(56.4)$ & $1.53(63.8)$ & $1.51(64.3)$ & \\
\hline GT-D18-1 & $2.16(60.5)$ & $1.85(60.3)$ & $1.70(70.0)$ & \multirow{2}{*}{$1.74(62.2)$} \\
\hline GT-D18-2 & $2.07(67.9)$ & $1.57(54.5)$ & $1.74(59.8)$ & \\
\hline GT-D20-1 & $2.16(64.9)$ & $1.92(69.6)$ & $1.67(75.9)$ & \multirow{2}{*}{$1.95(70.3)$} \\
\hline GT-D20-2 & $2.20(67.3)$ & $2.12(67.9)$ & $1.67(75.9)$ & \\
\hline
\end{tabular}

*Values in brackets represent \% of the recovery size to the end deflection of the continuous load. 


\section{Residual deformation of truss}

The residual deformation of the truss after unloading could be obtained from the second part of the load-displacement diagram of stage T2, as shown in Tab. 6. It could be seen from the table that the residual deformation of GT-D16 was the smallest, but only $0.09 \mathrm{~mm}$ different from that of GT-D20 truss. Therefore, the creep-resistant deformation ability of $16 \mathrm{~mm}$ dowel-connected girder trusses were similar to $20 \mathrm{~mm}$ dowel-connected girder truss, but the former was better.

\section{Ultimate bearing capacity of truss}

The residual deformation of the truss after unloading could be obtained from the second part of the load-displacement diagram of stage $T_{2}$, as shown in Tab. 6. It could be seen from the table that the residual deformation of GT-D16 was the smallest, but only $0.09 \mathrm{~mm}$ different from that of GT-D20 truss. Therefore, the creep-resistant deformation ability of $16 \mathrm{~mm}$ dowel-connected girder trusses were similar to $20 \mathrm{~mm}$ dowel-connected girder truss, but the former was better.

Tab. 6: Residual deformation of truss lower chord after T2 unloading (units: mm).

\begin{tabular}{|l|c|c|c|c|}
\hline Identifier of truss & Mid-span & Node E & Node F & Average \\
\hline ST & 1.29 & 0.93 & 0.9 & 1.04 \\
\hline GT-D16 & 0.82 & 0.66 & 0.70 & 0.73 \\
\hline GT-D18 & 0.97 & 1.12 & 1.04 & 1.04 \\
\hline GT-D20 & 1.05 & 0.85 & 0.55 & 0.82 \\
\hline
\end{tabular}

\section{Ultimate bearing capacity of truss}

In the destructive loading stage $T_{3}$, all trusses suffered from tooth plate separation failure at the bearing joints. However, the maximum bearing capacity of each truss was different due to the different performance of trusses and the influence of wood variability. The ultimate bearing capacity of various truss tests was shown in Fig. 11. The maximum bearing capacity of ST, GT-D16, GT-D18 and GT-D20 was $26.91 \mathrm{kN}, 55.68 \mathrm{kN}, 57.96 \mathrm{kN}$ and $60.42 \mathrm{kN}$ respectively. It could be seen that the ultimate bearing capacity of truss was GT-D20 > GT-D18 > GT-D16 > ST. The bearing capacity of the double girder trusses was 2.06-2.25 times that of two single trusses. According to the relationship between wood dowel diameter and ultimate bearing capacity of truss, they were proportional. The results showed that the bearing capacity of the triangular girder truss connected by $20 \mathrm{~mm}$ wood dowels was the strongest.

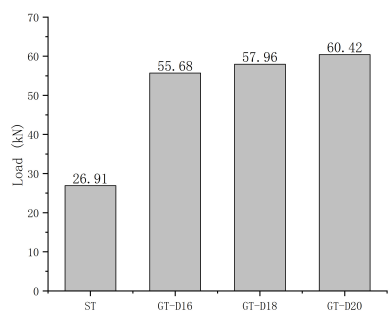

Fig. 11: Ultimate bearing capacity of various types of trusses.

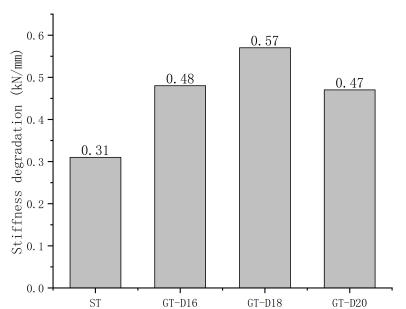

Fig. 12: Stiffness degradation. 


\section{Stiffness of truss}

The stiffness of the two-stage truss was obtained from the load-displacement diagrams of stage $T_{2}$ and stage $T_{3}$, respectively, as shown in Tab. 7 and Tab. 8. From Tab. 8, it could be seen that the stiffnesses of girder trusses were GT-D16 > GT-D18 > GT-D20 > ST. From Tab. 7 and Tab. 8, it could be seen that the stiffness degradation of the two stages trusses was obvious, and the degradation sizes were shown in Fig. 12. The stiffness degradation of GT-D18 was the greatest among the wood dowel-connected girder trusses, while GT-D16 and GT-D20 were smaller, which indicated that GT-D16 and GT-D20 had good synergy.

Tab. 7: Curve stiffness during loading in T2 stage (units: $k N \cdot m^{-1}$ ).

\begin{tabular}{|l|c|c|c|c|}
\hline Identifier of truss & Mid-span & Node E & Node F & Average \\
\hline ST & 1.11 & 1.27 & 1.44 & 1.27 \\
\hline GT-D16 & 1.88 & 2.22 & 2.27 & 2.12 \\
\hline GT-D18 & 1.66 & 1.99 & 2.34 & 2.00 \\
\hline GT-D20 & 1.62 & 1.66 & 2.15 & 1.81 \\
\hline
\end{tabular}

Tab. 8: Curve stiffness during loading in T3 stage (units: kN.mm-1).

\begin{tabular}{|l|c|c|c|c|}
\hline Identifier of truss & Mid-span & Node E & Node F & Average \\
\hline ST & 0.80 & 1.03 & 1.04 & 0.96 \\
\hline GT-D16 & 1.44 & 1.74 & 1.75 & 1.64 \\
\hline GT-D18 & 1.25 & 1.49 & 1.55 & 1.43 \\
\hline GT-D20 & 1.15 & 1.37 & 1.50 & 1.34 \\
\hline
\end{tabular}

\section{Discussion}

Researches on wood trusses mostly focus on the repair technology, metal tooth plate connection of single truss and light wood truss system. In contrast, the study of girder trusses has hardly been involved (Gupta et al. 2005, Gupta et al.2004, Rittenburg et al.2003, Via et al. 2001, Munafòet et al. 2015, Fauziyah et al. 2016, Underwood et al. 2001, Song et al. 2012, Gupta et al. 2004, Cabrero et al. 2009, Islam et al. 2017, Mohamadzadeh et al. 2015, Guntekin 2007, 2009, Sandanus et al. 2016, Moya et al. 2017) due to the common use of girder trusses in engineering, which has no design value reference. This raises several security issues. In the previous study (Wang et al. 2019, Gao 2017), the team members found that the connection of parallel chord girder trusses connected with wood dowels had a good synergistic effect and could effectively solve the instability problem of a single truss. So in order to explore the connection mode and performance between the trusses with different structural forms, this paper conducts experimental research on triangular girder trusses. It could be seen from the pre-loading stage that the residual deformation of the wood dowel-connected girder trusses were much smaller than that of the common wood trusses in previous research. The deflection value of corresponding joints at the loading stage of standard load was larger than that at the pre-loading stage, indicating that the increase of holding load would affect the deflection value, and the greater the holding load, the greater the deflection value. Under the same load, the length of load holding time had a certain influence on the deflection of truss during load holding period.

The support joint was the weak link of truss. The separation of the teeth started from the metal tooth plate at the support joint, then evolved into partial separation failure, and finally occurred complete separation failure. There was no significant failure phenomenon at other joints, 
and the load during the separation of the teeth was about two-thirds of the maximum load. After the separation failure of the support joint, loading continued. The second failure occurred for wooden trusses after they were loaded to the size of $P_{\mathrm{k}}$, which was the split failure of the wood at joint $\mathrm{B}$, indicating that the girder trusses had good safety.

Except for an indentation on the surface of the dowel with a diameter of $16 \mathrm{~mm}$, there was no obvious phenomenon in the other two kinds. The results showed that compared with two single trusses, the dowel-connected girder had better synergies. In the multiple wood trusses connected with wood dowels, the stiffness was inversely proportional to the ultimate bearing capacity, and inversely proportional to the diameter of the wood dowels.

\section{CONCLUSIONS}

Above all static loading tests were carried out on triangular girder truss with different diameter wood dowels. The following conclusions were obtained by analysing the experimental phenomenon of various types of trusses in the destructive loading stage $\mathrm{T}_{3}$ and the experimental data of preloading stage $T_{1}$, standard load loading $T_{2}$ and destructive loading stage $T_{3}$. From failure mode, the wood dowel joints still had structural load-carrying capacity after the first failure, and the second failure occurred when the continuous loading reached the $\mathrm{P}_{\mathrm{k}}$ value, which indicated that the girder truss connected by wood dowels had better safety. At the same time, there was a good synergy between the wood dowels and the girder trusses. The $20 \mathrm{~mm}$ wood dowel-connected girder truss had the best stability performance, the better bearing capacity of $60.42 \mathrm{kN}$ and deformation resistance of $0.82 \mathrm{~mm}$. From the ultimate bearing capacity of truss, the bearing capacity of the double girder trusses was 2.06-2.25 times that of two single trusses, which had the ability to 'one plus one is greater than two'. The energy dissipation performance of girder truss connected with $16 \mathrm{~mm}$ diameter wood dowel increased by $184 \%$ was the best and deformation resistance of $0.73 \mathrm{~mm}$, slightly better than the $16 \mathrm{~mm}$ one. From the comprehensive performance, the $20 \mathrm{~mm}$ wood dowel-connected girder truss had the best connection effect in the triangular girder trusses.

\section{ACKNOWLEDGMENTS}

This work was supported by the Special Fund for National Natural Science Foundation of China(Project No. 31670566) and National Key Technology Research and Development Program for the 12th Five-year Plan of China(No. 2015BAD14B05).

\section{REFERENCES}

1. Cabrero, J.M., Gebremedhin, K.G., 2009: Finite element model for predicting stiffness of metal-plate-connected tension-splice and heel joints of wood trusses. Transactions of the Asabe 52(2): 565-573.

2. Que, Z., Li, Z., Wang, F., Wang, Y., Wang, Y., 2015: Influence of high salinity environment on shear strength of wood frame structures. Industrial Construction 45(9): 81-85.

3. Fauziyah, S., Soesilohadi, R.C.H., Retnoaji, B., Alam, P., 2016: Dragonfly wing venous cross-joints inspire the design of higher-performance bolted timber truss joints. Composites Part B 87: 274-280. 
4. Gao, Y., 2017: Design and optimization of girder truss joints. Pp 20-41, Nanjing Forestry University.

5. GB/T 50329, 2012: Standard for test methods of timber structures. Profession standards of the People's Republic of China.

6. GB 50009, 2012: Load code for the design of building structures. Profession standards of the People's Republic of China.

7. Gupta, R., Miller,T.H., Kittel, M.R., 2005: Small-scale modeling of metal-plate-connected wood truss joints. Journal of Testing and Evaluation 33(3): 139-149.

8. Gupta, R., Miller, T.H., Redlinger, M.J., 2004: Behaviour of metal-plate-connected wood truss joints under wind and impact loads. Forest Products Journal 54(3): 76-84.

9. Gupta, R., Miller, T.H., Freilinger, S.M.W., 2004: Short-term cyclic performance of metal-plate-connected wood truss joints. Structural Engineering and Mechanics 17(5): 627-639.

10. Guntekin, E., 2007: Bending moment capacity of metal plate connected wood-splice joints constructed with red pine (Pinus brutia Ten.) lumber. Turkish Journal of Agriculture and Forestry 31(3): 207-212.

11. Guntekin, E., 2009: Performance of Turkish calabrian pine (Pinus brutia Ten.) timber joints constructed with metal plate connectors. Wood Research 54(3): 99-108.

12. He, S., Shang, P., Yang, B., Jiang, T., Yan, W., Zhu, Y.,2015: Influence of corrosion inducing treatment on shear behavior of bamboo nail and steel nail. China Forestry Science and Technology 29(2): 90-94.

13. Islam, A.K.M.A., Phillips, D., 2017: An experimental analysis of a timber Howe truss. Structures 10:39-48.

14. Madsen, B., 1992: Structural behavior of timber. Engineering Ltd. Vancouver, 10 pp.

15. Mohamadzadeh, M., Hindman, D.P., 2015: Analysis of metal plate connected wood truss assemblies under out-of-plane loads. Structures Congress 2015: 2021-2031.

16. Prochazka, J., Bohm, M., Svitak, M., 2014: Diverse influence of user-economic aspects to truss and rafter roof systems and their comparison. Wood Research 59(3): 449-458.

17. Rittenburg, K.A.W., Kunnath, S.K., 2003: Deflection of metal plate connected wood trusses with nontriangulated openings. Journal of Structural Engineering-ASCE 129(11): 1546-1558.

18. Moya, R., Tenorio, C., 2017: Strength and displacement under tension and compression of wood joints fastened with nails and screws for use in trusses in Costa Rica. Wood Research 62(1): 139-155.

19. Munafò P., Stazi F., Tassi C., Davì F., 2015: Experimentation on historic timber trusses to identify repair techniques compliant with the original structural-constructive conception. Construction and Building Materials 87(15): 54-66.

20. Underwood, C.R., Woeste, F.E., Dolan,J.D., Holzer, S.M., 2001: Permanent bracing design for MPC wood roof truss webs and chords. Forest Products Journal 51(7-8): 73-81.

21. Song, X., Lam, F., 2012: Stability analysis of metal-plate-connected wood truss assemblies. Journal of Structural Engineering 138(9): 1110-1119.

22. Sandanus, J., Sogel, K., Slivansky, M., 2016: Results of rheological test on timber trusses. Wood Research 61(2): 235-242.

23. Via, B.K., Zink-Sharp, A., Woeste, F., Dolan, J.D., 2001: Influence of specific gravity on embedment gaps in metal-plate-connected truss joints. Forest Products Journal 51(10): 8892. 
24. Wang, F., Teng, Q., Gao, Y., Chen, Q., Wang, C., Que, Z., 2019: Static load test and bearing capacity of timber girder truss. Journal of Civil and Environmental Engineering 41(2): 86-92.

25. Zhang, J., Zhong, Y., Zhao, R., Zhou, H., 2012: Reviews of mechanical properties for timber bolted joints. China Wood Industry (04): 39-42.

26. Yang, X.J., Zhao, Q. Hao, D., Wang, J.Y., Fu, S., Ma, L., 2020: Flexural behavior of OSB reinforced wood truss. Wood Research 65(2): 245-256.

27. Yang, L., 2014: The influence on properties of wood structure in high temperature high humidity and high salinity. Pp 15-36, Nanjing Forestry University.

28. GB/T 1928, 2009: General requirements for physical and mechanical tests of wood. Profession standards of the People's Republic of China.

\author{
Liuliu Zhang, Cheng Chang, Shuming Yang, \\ Tongyu Hou, Yifan Liu, Zeli Que* \\ Nanjing Forestry University \\ College Of Material Science And Engineering \\ Nanjing 210037 \\ P.R. CHina \\ "Corresponding author: zelique@njfu.edu.cn
}

